\title{
Pulmonary Functions After Injection Sclerotherapy Of Esophageal Varices \& After Band Ligation
}

\author{
Mohamed A. Metwally*, Ahmad Abdelsadek Mohammad,**Galal A. Moawad,*. \\ Hepatology, Gastroenterologytious Diseases Department -Benha University (*), Chest \\ Department -Benha University (**)
}

\begin{abstract}
Aim of the study: To study changes in pulmonary function tests after esophageal variceal injection sclerotherapy in comparison to changes after esophageal variceal band ligation.

Patients \& methods:

This study was designed as non randomized controlled study. Thirty patients with hepatic cirrhosis \& portal hypertension who were admitted to Hepatology, Gastroenterology and Infectious Diseases department, Benha university hospital for elective esophageal variceal therapy (secondary prophylaxis) were classified into group I:15 patients treated with sclerotherapy by using 5-15 ml ethanolamine oleate and group II: 15 patients treated with band ligation. Patients were subjected for full clinical evaluation including history, general, chest, and abdominal examination. Laboratory and radiological investigation including complete blood count, liver function tests, kidney function tests and blood sugar and plain chest x-ray (P.A. and lateral views) were done. Pulmonary function tests and arterial blood gasses were done before, one day after and one week after the procedure.
\end{abstract}

Results:

The results revealed, significant decrease in vital capacity in group I one day after injection ( $p$ $<0.05$ ), but no significant decrease in vital capacity in group II. There was a significant decrease in $\mathrm{PaO} 2$ in group I one day after injection sclerotherapy $(\mathrm{p}<0.05)$ but no significant changes in group II and no significant changes in $\mathrm{PaCO} 2$ in both groups one day after the procedures. The study has also revealed no significant changes in FVC,FEV1/FVC and $\mathrm{PaCO} 2$ in group I and group II after procedures. The study revealed significant linear correlation between the decreases in $\mathrm{PaO} 2$ and the percentage decrease in vital capacity $(\mathrm{p}<0.05)$. One week after procedure, pulmonary functions that has been affected in group I returned back to baseline values.

Conclusions: esophageal injection sclerotherapy produces restrictive defect (decrease in $\mathrm{PaO} 2$ and vital capacity) in pulmonary functions one day after injection and improved within one week, while there was no effect for band ligation on pulmonary functions tests.

Key words: esophageal varices, sclerotherapy, band ligation, pulmonary functions test.

\section{Introduction}

Esophageal varices are extremely dilated sub-mucosal veins in the lower third of the esophagus[1]. They are most often a consequence of portal hypertension, commonly due to cirrhosis and one of the common causes of upper gastrointestinal bleeding. Diagnosis of variceal bleeding or risk of bleeding is done by upper gastrointestinal endoscopy [2]. Variceal bleeding is a major complication of portal hypertension and represents a leading cause of death in patients with cirrhosis. Diagnostic and therapeutic developments have led to a significant improvement in the prognosis of variceal bleeding [3].
Endoscopic therapies for varices aim to reduce variceal wall tension by obliteration of the varix. The two principal methods available for esophageal varices endoscopic therapy are endoscopic sclerotherapy (EST) and endoscopic band ligation (EBL). Endoscopic therapy is a local treatment that has no effect on the pathophysiological mechanisms that lead to portal hypertension and variceal rupture. However, a spontaneous decrease in hepatic venous pressure gradient occurs in around $30 \%$ of patients treated with either EST or EBL to prevent variceal rebleeding [4].

The complications of injection sclerotherapy have been extensively reviewed [5].They can be divided broadly 
into two categories, those occurring at the site of injection and those resulting from systemic dissemination of the sclerosant through the paraoesophageal and azygos veins; this has been shown radiologically [6]. Abnormalities of organ function have been described including abnormal chest radiology [7], and rarely respiratory failure [8]. Pulmonary complications are common and range from minor asymptomatic changes found incidentally on routine chest radiographs to aspiration or bronchopneumonia, pleural effusions, lobar collapse or consolidation, adult respiratory distress syndrome [9], bronchoesophageal fistula [10] , pneumothorax [11] , subcutaneous emphysema[12] and chylothorax [13] .

\section{Aim of the study}

To study changes in pulmonary function tests after esophageal variceal injection sclerotherapy in comparison to changes after band ligation.

\section{Patients \& methods}

This study was designed as non randomized controlled study. It was conducted on 30 patients with hepatic cirrhosis and portal hypertension who were admitted to Hepatology, Gastroenterology and Infectious Diseases department, Benha university hospital between January 2009 and December 2009 for elective (secondary prophylaxis) esophageal variceal therapy. Patients were classified into 2 groups:

Group I: 15 patients treated with elective intravariceal injection sclerotherapy by using 5-15 $\mathrm{ml}$ ethanolamine oleate without anesthesia or sedation.

Group II: 15 patients treated with band ligation of their esophageal varices without anesthesia or sedation .

All groups were subjected for

1- Full history taking.

2- Plain chest $X$ ray(P.A. and lateral view), before \& 24 hours after procedures.

3- Complete blood count

4- Liver functions.

5- Blood urea and serum creatinin..

6- Abdominal ultrasound

7-Pulmonary function tests were done using Sensor-medics V max series, 2130 spirometer, V6200 Autobox, 6200DL before, one day after the procedure and after one week of endoscopic variceal therapy.

8-Arterial blood gases using ABL2 blood gas apparatus was examined. First sample was obtained before treatment, second sample one day after procedure and $3^{\text {rd }}$ sample after one week. Blood samples were obtained from the radial artery with patient propped up in bed at about $60^{\circ}$.

\section{Exclusion criteria :}

\section{A- Before procedure}

- History of chronic chest disease as bronchial asthma or COPD.

-Associated medical condition that may affect pulmonary function test e.g. ascitis

- Any chest complaint e.g. chest pain ,shortness of breath

- Abnormal chest x ray, including consolidation or pleural effusion.

\section{A- After procedure}

- Chest pain which might be expected to affect respiration functions.

- Dysphagia

- Fever

- Abnormal chest x ray

Statistical analysis of the collected data was done by using Student's two tailed t test for paired and unpaired data as appropriate and Linear Correlation Coefficient analysis test by SPSS V [14] .

\section{Discussion}

Sclerotherapy has proven to be inferior to band ligation for primary and secondary prophylaxes of variceal hemorrhage, due to a higher number of complications, and the fact that more sessions are required to achieve variceal obliteration [15]. However, ESC has still been found to be similar to EBL for control of bleeding in some studies[16].

This study was performed to compare between effect of injection sclerotherapy of esophageal varices and band ligation on pulmonary functions. The study was performed on 30 patients with hepatic cirrhosis \& portal hypertension and classified into 2 groups:

Group I:15 patients scheduled to have elective sclerotherapy of their esophageal varices

Group II:15 patients scheduled to have band ligation of their esophageal varices . 
The demographic data of the studied subjects included in this study are illustrated in table (1). Group I included 15 patients ( 9 male \& 6 female) ,their mean age was $49.53 \pm 6.57$ years, their mean weight was $56.4 \pm 9.26 \mathrm{~kg}$ and Child's classification (A:3, B:8, C:4). While group II included 15 patients ( 8 male \& 7 female), their mean age was $50.53 \pm 6.59$ years, their mean weight was $59.53 \pm 8.89$ kg.and Child's classification (A:5, B:7, C:3). There is no significant difference between the two groups regarding demographic data or child classification.

The pulmonary functions before \& one day after injection sclerotherapy were illustrated -in the same arrangement- in table (2). Vital capacity (VC) was 4.24 \pm 0.39 liters before and $3.89 \pm 0.08$ liters after therapy $(\mathrm{P}<0.05)$. FEV1 $=3.6 \pm 0.33$ liters before and $2.4 \pm 0.34$ liters after therapy $(\mathrm{P}<0.05)$. FVC $=4.4 \pm 0.37$ liters before and $3.0 \pm 0.39$ liters after therapy $(\mathrm{P}$ $<0.05)$. FEV1/FVC $\%=76.35 \pm 4.2$ before and 75.42 \pm 3.9 after therapy ( $\mathrm{P}>0.05$ ). $\mathrm{PaO} 2=94.1 \pm 2.12 \mathrm{~mm} \mathrm{Hg}$ before and $86.4 \pm 1.89 \mathrm{~mm} \mathrm{Hg}$ after therapy $(\mathrm{P}<0.05)$. $\mathrm{PaCO} 2=40.1 \pm 2.64 \mathrm{~mm} \mathrm{Hg}$ before and $40.9 \pm 2.77 \mathrm{~mm} \mathrm{Hg}$ after therapy $(\mathrm{P}>0.05)$.

Pulmonary functions before \& one day after band ligation in group II- in the same arrangement- were VC $=4.42 \pm 0.48$ liters before and $4.33 \pm 0.41$ liters after therapy $(\mathrm{P}>0.05)$. FEV1 $=3.57 \pm 0.32$ liters before and 3.48 \pm 0.30 liters after therapy ( $\mathrm{P}$ $>0.05)$. FVC $=4.3 \pm 0.81$ liters before and $4.2 \pm 0.79$ liters after therapy $(\mathrm{P}>0.05)$. FEV1/FVC\% $=78.56 \pm 4.6$ before and $76.99 \pm 4.9$ after therapy $(\mathrm{P}>0.05) . \mathrm{PaO} 2$ $(\mathrm{mm} \mathrm{Hg})=94.5 \pm 2.35 \mathrm{~mm} \mathrm{Hg}$ before and $94.3 \pm 2.5 \mathrm{~mm} \mathrm{Hg}$ after therapy $(\mathrm{P}>0.05)$. $\mathrm{PaCO} 2=39.3 \pm 2.13 \mathrm{~mm} \mathrm{Hg}$ before and $39.5 \pm 2.27 \mathrm{~mm} \mathrm{Hg}$ after therapy $(\mathrm{P}>0.05)$. These results revealed, significant decrease in vital capacity in group I after injection ( $\mathrm{p}<0.05$ ), but no significant decrease in vital capacity in group II after band ligation. There is significant decrease in FVC in group I after injection $(\mathrm{p}<0.05)$, but no significant decrease in FVC in group II.And a significant decrease in FEV1 in group I after injection $(\mathrm{p}<0.05)$ but no significant decrease in FEV1 in group II. No significant changes in $\mathrm{FEV} 1 / \mathrm{FVC} \%$ in group I or group IIafter procedures ( $p$
$>0.05)$. There was significant decrease in $\mathrm{PaO} 2$ in group I one day after injection sclerotherapy $(\mathrm{p}<0.05)$ but no significant changes in group II and no significant changes in $\mathrm{PaCO} 2$ in both groups before and after the procedures. These results are in agreement with the study done by Samuli et al., [17] who studied pulmonary function tests in 12 patients received injection sclerotherapy by using ethanol amine oleate under general anesthesia in comparison to 9 subjects had only esophagoscpy under general anesthesia.They did pulmonary function test one day after procedure to be sure of elimination of possible effect of anesthesia or sedation on pulmonary function . They found that, the vital capacity decreased by 0.39 liter $(\mathrm{p}<0.05)$ in patients who received injection sclerotherapy but did not change in non injected group. $\mathrm{PaO} 2$ in injected group was $94.8 \mathrm{~mm} \mathrm{Hg}$ then decreased by $9.3 \mathrm{mmHg}$ after one day from injection $(\mathrm{p}<0.05)$.while in non injected group before endoscopy was $93.8 \mathrm{mmHg}$ and after endoscopy was $93.8 \mathrm{mmHg}$. This study also revealed no significant changes in FVC,FEV1/FVC and $\mathrm{PaCO} 2$ in group I and group II before and after procedures . Also our results are in agreement with the study done by Pradeepta et al., [18] where they studied twenty-six patients with portal hypertension of different etiologies. Patients were subjected to variceal sclerotherapy using absolute alcohol, they found significant decline in FVC, FEV1 after sclerotherapy as compared with baseline values however FEV1/FVC ratio did not change significantly.

These changes in respiratory function could be explained by, embolisation of sclerosant to the lung, but other possibilities include intravascular platelet aggregation is postulated [19]. Another explanation for the decrease in $\mathrm{PaO} 2$ could be the severity of the cirrhosis. Porto- systemic shunting of blood occurs in decompensated cirrhosis and this results in the delivery of endotoxins directly from the gut to the systemic circulation. This can affect platelet aggregation mechanisms, coagulation, and ultimately pulmonary functions[20].

The present study revealed significant linear correlation between the 
decreases in $\mathrm{PaO} 2$ and the percentage decrease in vital capacity $(\mathrm{p}<0.05)$ figure(1). These results are in agreement with the study done by Samuli et al. [17] .The close correlation between the decrease in $\mathrm{PaO} 2$ and the fall in vital capacity suggest that a decrease in lung volume was the probable cause of the drop in $\mathrm{PaO} 2$ described here and resulting perhaps from a decrease in compliance. The most probable explanation would be sclerosant embolisation by the paraoesophageal and azygos veins to the lung resulting in areas of alveolar exudate and consolidation with increase in lung stiffness and pulmonary shunt. There is evidence that sclerosant dissemination to the pulmonary and systemic circulation after intravariceal sclerotherapy occurs through esophagogastric collaterals and the azygoushemiazygous systems[19] .Entry of sclerosant into the pulmonary circulation has been demonstrated to occur by positive uptake on lung scan of technetium- $99 \mathrm{~m}$ (Tc99m)-tagged sodium morrhuate (SM) and sodium tetradecyl sulfate(STS) solutions when injected into esophageal varices[6].

The comparison of pulmonary functions in group I before\& after one week from injection sclerotherapy-in the same arrangement- in table (3) were VC $=4.24$ \pm 0.39 liters before and $4.05 \pm 0.48$ liters one week after therapy $(\mathrm{P}>0.05)$. FEV1 $=3.6 \pm$ 0.33 liters before and $3.44 \pm 0.30$ liters one week after therapy $(\mathrm{P}>0.05) . \mathrm{FVC}=4.4 \pm$ 0.37 liters before and $4.5 \pm 0.39$ one week after therapy ( $\mathrm{P}>0.05)$. FEV1/FVC\% $=76.35 \pm 4.2$ before and $77.35 \pm 4.3$ one week after therapy $(\mathrm{P}>0.05) . \mathrm{PaO} 2=94.1 \pm 2.12$ $\mathrm{mm} \mathrm{Hg}$ before and $93.1 \pm 1.98 \mathrm{~mm} \mathrm{Hg}$ one week after therapy $(\mathrm{P}>0.05) . \mathrm{PaCO} 2=$ $40.1 \pm 2.64 \mathrm{~mm} \mathrm{Hg}$ before and $40.3 \pm 2.34$ one week after therapy $(\mathrm{P}>0.05)$. These results revealed improvement of pulmonary function and returning to the basal level after one week from sclerotherapy. These findings could be explained by that ,the deleterious effect of sclerotherapy on pulmonary functions are transient and reversible [7].

\section{Conclusion}

Patients undergoing elective esophageal injection sclerotherapy develop a restrictive defect (decrease in $\mathrm{PaO} 2$ and vital capacity) in pulmonary function one day after the procedure; these decreases are transient and subside within one week. On the other hand no effect for esophageal band ligation on respiratory function test.

\section{Results}

We included in this study 30 patients with age ranging from 41 to 63 years. Table 1 showed that there was no significant difference between patients treated with injection sclerotherapy and those treated with band ligation regarding baseline demographic factors or stage of cirrhosis. Comparison of pulmonary functions preprocedure and one day after the procedure in both groups showed that $\mathrm{VC}$, FEV1, and $\mathrm{PaO} 2$ has been significantly decreased after injection sclerotherapy but not affected with band ligation (Table 2). We found also a significant positive correlation between changes in vital capacity and changes in $\mathrm{PaO} 2$ (Fig.1).

Follow up pulmonary functions tests after one week of the procedures showed that VC, FEV1, and $\mathrm{PaO} 2$ that has been decreased one day after procedure have returned back to baseline (Table 4).

\section{References}

1- Rubin's Pathology (2007) :Clinicopathologic Foundations of Medicine edited by Raphael Rubin, David S. Strayer, Emanuel Rubin, page 612.

2- Biecker E, Schepke M, Sauerbruch T (2005). "The role of endoscopy in portal hypertension". Dig Dis 23 (1): 117. doi:10.1159/000084721.PMID 15920321.

3-Abid S, Jafri W, Hamid S, et al. (2009). "Terlipressin vs. octreotide in bleeding esophageal varices as an adjuvant therapy with endoscopic band ligation: a randomized doubleblind placebo-controlled trial". Am. J. Gastroenterol., 104 (3): 617-23.

4- Villanueva C, Colomo A, Aracil C, Guarner C. (2008).Current endoscopic therapy of variceal bleeding. Best Pract Res Clin Gastroenterol.,;22:261-278.

5- Bornman PC, Krige JEJ, Terblanche J. (1994). Management of oesophageal varices. Lancet 343: 1079-1084.

6- Krige JE, Bornman PC. (2000). Endoscopic treatment of oesophageal varices. S Afr J Surg 38: 82-88 .

7- Krige JE, Beckingham I.J. (2001) Portal hypertension: varices. BMJ 322: 348-351. 
8- D’Amico G, Pagliaro L, Bosch J. (1995) The treatment of portal hypertension : a metaanalytic review. Hepatology 22: 332-354

9- Baydur A, Korula J.( 1990). Cardiorespiratory effects of endoscopic esophageal variceal sclerotherapy. Am J Med; 89: 477-482.

10- Carr-Locke DL, Sidky K.( 1982). Bronchooesophageal fistula: a late complication of endoscopic variceal sclerotherapy. Gut 23: 1005-1007-

11- Alwmark A, Bengmark S, Borjesson B.(1982).Emergency and long term transesophageal sclerotherapy of bleeding esophageal varices. Scand J Gastroenterol; 17: 409-412.

12- Barsoum MS, Mooro HA, Bolous FI, Ramzy AF, Rizk-Allah MA Mahmoud FI. (1982) The complications of injection sclerotherapy of bleeding oesophageal varices. Br J. Surg 69: 79-81.

13- Gertsch P, Mosimann R. (1983). Chylothorax complicating sclerotherapy for bleeding oesophageal varices. Br J Surg 70: 562566 .

14- Yadolah (2003): The Oxford Dictionary of Statistical Terms. Oxford University Press. ISBN 0-19-920613-9.
15- Kochhar R, Goenka MK, Mehta S.(1990).A comparative evaluation of sclerosants for esophageal varices: a prospective randomized controlled study. Gastrointest Endosc 36:127-30. 16- Helmy A, Hayes PC. (2001).Review article: current endoscopic therapeutic options in the management of variceal bleeding. Aliment Pharmacol Ther. 15:575-94.

17-T Samuels, M C Lovett, I T Campbell, C Makin, J Davies, S A Jenkins, J N Baxter. (1994).Gut 35: 1459-1463

18-Pradeepta K Sethy , Rakesh Kochhar , Digambar Behera, Deepak K Bhasin, Kaiser Raja, Kartar Singh (2003).Journal of Gastroenterology and Hepatology,

8): 910-914.

19- Karacagil S, Lane IF, McCollum CN, Irwin JTC, Poskitt KR.(1986). Is organ failure after variceal sclerotherapy caused by microembolism? Br.J7 Surg 73: 507.

20- Shehata, M. E. A.; Azzam, F.; El-Fiky, A.; El-Morsi, A.; Khaled, A. (1990).

Pleural and mediastinal changes following endoscopic variceal sclerotherapy in bilharzial patients.Journal of Tropical MedicineVol. 1 No. 1 pp. $125-130$

Table (1): demographic data for the 2 studied groups.

\begin{tabular}{|c|c|c|c|}
\hline & Group I $(\mathrm{N}=15)$ & Group II $(\mathrm{N}=15)$ & \\
\hline & & & P- value \\
\hline $\begin{array}{l}\text { Age(year), mean } \pm \text { SD } \\
\text { Range (median) }\end{array}$ & $\begin{array}{l}49.53 \pm 6.57 \\
41-60(\text { median } 51)\end{array}$ & $\begin{array}{l}50.53 \pm 6.59 \\
43-63 \text { (median 53) }\end{array}$ & $>0.05$ \\
\hline Sex, Male, No (\%) & $9(60 \%)$ & $8(53.3 \%)$ & $>0.05$ \\
\hline $\begin{array}{l}\text { Weight }(\mathrm{kg}), \text { mean } \pm \text { SD } \\
\text { Range (median) }\end{array}$ & $\begin{array}{l}56.4 \pm 9.26 \\
76(\text { median } 63)\end{array}$ & $\begin{array}{l}59.53 \pm 8.89 \\
77(\text { median } 65)\end{array}$ & $>0.05$ \\
\hline $\begin{array}{l}\text { Child's classification } \\
{[\text { No }(\%)]} \\
\text { A } \\
\text { B } \\
\text { C }\end{array}$ & $\begin{array}{l}3(20 \%) \\
8(53.3 \%) \\
4(26.7 \%)\end{array}$ & $\begin{array}{l}3(20 \%) \\
8(53.3 \%) \\
4(26.7 \%)\end{array}$ & $>0.05$ \\
\hline
\end{tabular}

Table (2): Pulmonary function before and one day after the procedure:




Figure (1): Correlation between change in vital capacity and change in $\mathrm{PaO} 2$ in group I one day after injection sclerotherapy

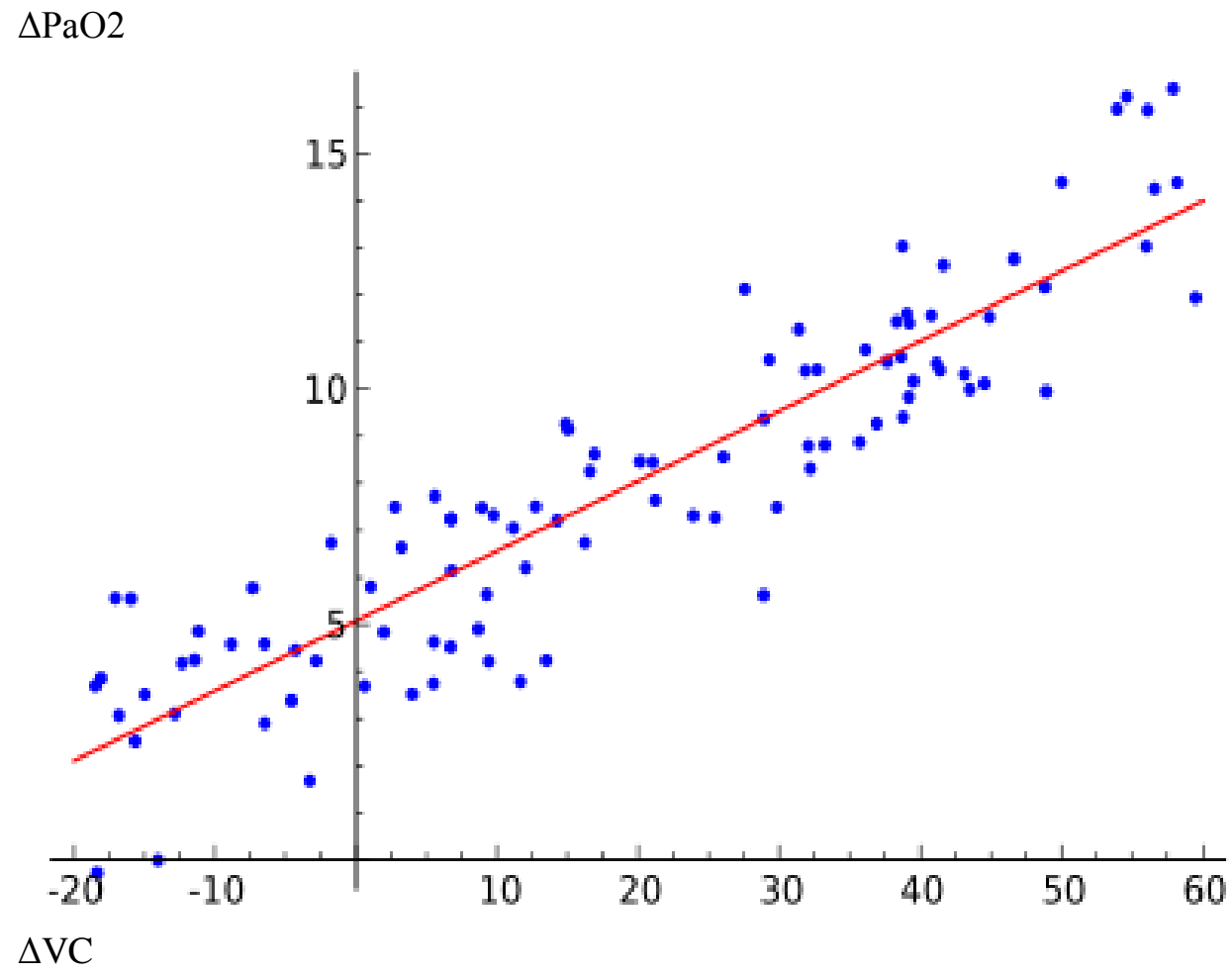

Table(3) : Pulmonary functions in group I before injection and one week after injection sclerotherapy

\begin{tabular}{|l|l|l|l|}
\hline \multicolumn{2}{|l|}{} & Group I & After \\
\hline & Before & $4.05 \pm 0.48$ & P value \\
\hline VC (liters) & $4.24 \pm 0.39$ & $3.44 \pm 0.30$ & $>0.05$ \\
\hline FEV1 & $3.6 \pm 0.33$ & & $>0.05$ \\
& & $4.5 \pm 0.39$ & \\
\hline FVC(liters) & $4.4 \pm 0.37$ & $77.35 \pm 4.3$ & $>0.05$ \\
\hline FEV1/FVC\% & $76.35 \pm 4.2$ & $93.1 \pm 1.98$ & $>0.05$ \\
\hline $\mathrm{PaO} 2(\mathrm{~mm} \mathrm{Hg})$ & $94.1 \pm 2.12$ & $40.3 \pm 2.34$ & $>0.05$ \\
\hline $\mathrm{PaCO} 2(\mathrm{~mm} \mathrm{Hg})$ & $40.1 \pm 2.64$ & $>0.05$ \\
\hline
\end{tabular}

